DE

M E D I C I N A

T R O P I C A L

$\mathrm{DE}$

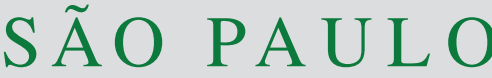

JOURNAL OF THE SÃO PAULO INSTITUTE OF TROPICAL MEDICINE

1 Universidade de São Paulo, Faculdade de Medicina, Hospital das Clínicas, Centro de Referência para Imunobiológicos Especiais, São Paulo, São Paulo, Brazil

Correspondence to: Amanda Nazareth Lara

Universidade de São Paulo, Faculdade de Medicina, Hospital das Clínicas, Centro de Referência para Imunobiológicos Especiais, Av. Dr. Enéas de Carvalho Aguiar, 155,

Prédio dos Ambulatórios, $4^{\circ}$ andar, bloco 8, Cerqueira César, CEP 05403-000 São Paulo, SP, Brazil

Tel: +55 11 2661-7517

E-mail: amanda.lara@hc.fm.usp.br

Received: 19 August 2020

Accepted: 15 October 2020

\section{Adverse events following yellow fever vaccination in immunocompromised persons}

\author{
Amanda Nazareth Lara ${ }^{\circledR 1}$, Karina Takesaki Miyaji ${ }^{\circledR 1}$, Karim Yaqub Ibrahim ${ }^{(1)}$, \\ Marta Heloisa Lopes ${ }^{\circledR 1}$, Ana Marli Christovam Sartori ${ }^{\circledR 1}$
}

\section{ABSTRACT}

This observational retrospective study conducted during an yellow fever (YF) outbreak in Sao Paulo, Brazil, in 2017-2018, describes adverse events (AE) following YF vaccination of immunocompromised persons. Risks and benefits of vaccination were individually evaluated by physicians. AE were assessed by phone call or electronic mail, 14 to 90 days after vaccination. Three hundred and eighty one immunocompromised persons received a full-dose of YF vaccine. Their age ranged from 1.4 to 89.3 years (median 50.8 years); $53 \%$ were women; 178 (46.7\%) had chronic kidney disease, 78 (20.5\%) had immune-mediated inflammatory diseases; 94 (24.7\%) were using or had recently used immunosuppressive/ immunomodulatory drugs. All of them denied previous YF vaccination. We were able to contact $341(89.5 \%)$ vaccinees: $233(68.3 \%)$ of them received the YF vaccine from BioManguinhos and 108 (31.7\%) received the vaccine from Sanofi-Pasteur; 130 (38.1\%) vaccinees received other vaccines (up to 4 ) simultaneously with the the YF vaccine, mostly hepatitis B (59 vaccinees), pneumococcal polysaccharide 23-valent (46), influenza (43) and diphtheria-tetanus (dT, 41). One hundred and eleven vaccinees $(32.6 \%)$ reported at least one AE: 79 (23.2\%) presented systemic AE, 44 (12.9\%) had local AE and 12 had both, local and systemic AE. The most common AE was pain at the injection site (41 persons, $12 \%$ ), myalgia $(34 ; 10 \%)$, fever $(25 ; 7.3 \%)$ and headache $(16 ; 4.7 \%)$. There was no statistically significant difference on the AE frequency according to the vaccine producer. There were four severe AE: one hospitalization and three deaths, considered not related to the YF vaccine.

KEYWORDS: Adverse events following immunization. Yellow fever vaccine. Immunosuppression. Chronic renal failure. Autoimmune conditions.

\section{INTRODUCTION}

Yellow fever (YF) urban transmission has been interrupted in Brazil since 1942, but sylvatic YF, historically endemic in the Brazilian Amazon and Midwest regions, has expanded to the East and South since the early 2000 s $^{1}$. From time to time, YF reemerges in the country, producing outbreaks of varied magnitudes and extent. In the late 2016, human YF cases were reported in a previously transmission-free area in Minas Gerais State, in the Southeastern of Brazil, triggering the largest outbreak in several decades. The outbreak expanded to previously YF-free areas in the neighbor States of Espirito Santo, Rio de Janeiro and Sao Paulo, a highly populated area ${ }^{1}$. From December 2016 to July 2017, 777 confirmed human YF cases and 261 deaths were reported ${ }^{2}$. In the following season, from July $1^{\text {st }}, 2017$ to June 30, 2018, 1,376 confirmed human YF cases and 483 deaths were registered ${ }^{3}$. The sylvatic cycle was responsible for all human cases, but YF re-urbanization was a concern, due to the 
great number of human YF cases in large urban centers with high densities of Aedes aegypti infestation and low YF vaccine coverage ${ }^{4}$.

YF vaccination was expanded to the entire population living in areas without prior vaccine recommendations, in which the outbreaks took place ${ }^{5}$. The search for the YF vaccine has hugely increased in Sao Paulo city, as the forests around the State capital have become transmission areas. Health services had to attend the population that was queuing to receive the vaccine. Those with underlying conditions were referred to reference centers to see if they could be vaccinated.

Despite being safe, the YF live attenuated vaccine can rarely cause severe illnesses, such as acute neurologic disease $(0.2$ cases per 100,000 doses $)$ or vaccineassociated viscerotropic disease (YEL-AVD) (0.04 cases per 100,000 doses $)^{6,7}$. Vaccine contraindications include children under six months of age, pregnant women, immunocompromised persons, those with a history of thymus disease, and those who had anaphylactic reactions to the vaccine components. Given the high risk of YF transmission at that time, panels of experts in immunodepression/ immunosuppression conditions and vaccinologists standardized YF vaccination criteria for some groups of immunocompromised persons, such as those with immuno-mediated rheumatic diseases (IMRD) ${ }^{8}$.

The aim of this study is to report the adverse events following immunization (AEFI) in immunocompromised persons who received the YF vaccine at a reference center in Sao Paulo.

\section{MATERIAL AND METHODS}

This observational retrospective study was conducted at the Reference Center for Special Immunobiologicals (Centro de Referencia para Imunobiologicos Especiais - CRIE) of the Hospital das Clinicas (HC), a tertiary/quaternary hospital attached to the University of Sao Paulo Medical School (FMUSP), in Sao Paulo city, from September 2017 to December 2018. Immunocompromised persons due to chronic conditions or immunosuppressive therapy, who searched or were referred to the CRIE to receive the YF vaccine, were screened by the physicians regarding the risks and benefits of their vaccination. The YF vaccine recommendation was individualized, taking into account the type, severity and activity of the underlying condition and the degree of immunosuppression. We used the criteria of the Brazilian Society of Rheumatology, Brazilian Society of Infectious Diseases and Brazilian Society of Tropical Medicine on YF vaccination of patients with $\mathrm{IMRD}^{8}$, to recommend the YF vaccination to: clinically stable persons with low grade immunosuppression, defined by a singledrug therapy with: hydroxychloroquine or sulfasalazine (any dosage); corticosteroids in prednisone equivalence dosage $\leq 2 \mathrm{mg} / \mathrm{kg}$ or $\leq 20 \mathrm{mg}$ daily; methotrexate $($ MTX) $\leq$ $0.4 \mathrm{mg} / \mathrm{kg}$ or $\leq 20 \mathrm{mg}$ weekly; or leflunomide $\leq 20 \mathrm{mg} / \mathrm{day}^{8}$. The YF vaccine was contraindicated for persons taking methylprednisolone pulse therapy, mycophenolate mofetil, cyclosporine, cyclophosphamide, azathioprine, JAK inhibitors, such as tofacitinib, and biological immunomodulators ${ }^{8}$. Whenever other conditions, such as chronic kidney and liver diseases, neurologic diseases, and cancer were present, YF vaccine recommendations were discussed by the CRIE staff with experts of the HC. The YF vaccination was recommended, by the attending physicians, for immunocompromised clinically stable persons whose exposure was considered high, in such a way that the benefits of vaccination were considered to outweigh its risks. All vaccinees received a full-dose of YF $17 D D$ vaccine. They were oriented regarding the AEFI and advised to return to the CRIE in such case. Authorization for a post-vaccination contact, through phone call or electronic message (email, WhatsApp) to assess the AEFI was asked for all vaccinees with chronic conditions.

Local and systemic AEFI were evaluated by a standard form, applied by phone call or electronic message. The following data was collected: age, underlying conditions, drugs in use and adverse events. Solicited AEFI were pain, edema and erythema at the injection site, fever, headache and myalgia. Unsolicited AEFI were any other events reported by vaccinees. AEFI intensity and dates of start and end were also collected. Contact with the participants was made from 14 to 90 days after vaccination and at least three contact attempts were made for each participant.

This report was approved by the Ethical Committee of the Department of Infectious and Parasitic Diseases of FMUSP ( $\left.{ }^{\circ} 004 / 20\right)$.

\section{RESULTS}

During the study period, 29,595 YF vaccine doses were administered at the CRIE. Most vaccinees had no vaccine contraindication; 571 persons with chronic conditions, using or not immunosuppressive therapy, had a pre-vaccination evaluation and $381(66.7 \%)$ of them were vaccinated and included in this report (Table 1).

The vaccinees age ranged from 1.4 to 89.3 years (mean, 48.6 and median, 50.8 years); $53 \%$ of them were women. All of them denied prior YF vaccination. Among the 381 vaccinees, the most common underlying conditions was chronic kidney disease (CKD) (178 participants, 46.7\%), mostly dialytic (79.8\%); immune-mediated inflammatory 
Table 1 - Characteristics of immunocompromised persons screened for the yellow fever (YF) vaccination at the Reference Center for Immunobiologicals (CRIE) of Hospital das Clinicas of University of Sao Paulo Medical School, from September 2017 to December 2018.

\begin{tabular}{|c|c|c|}
\hline Characteristics & $\begin{array}{l}\text { YF vaccine was not } \\
\text { recommended }(n=190)\end{array}$ & $\begin{array}{c}\text { YF vaccine was } \\
\text { recommended }(n=381)\end{array}$ \\
\hline \multicolumn{3}{|l|}{ Age (years) } \\
\hline Min-Max. & $0.9-92$ & $1.4-89.3$ \\
\hline Median & 54.5 & 50.8 \\
\hline Mean & 51.8 & 48.7 \\
\hline Female gender & $130(68.4 \%)$ & $202(53.0 \%)$ \\
\hline \multicolumn{3}{|l|}{ Underlying conditions } \\
\hline Chronic kidney diseases & $12(6.3 \%)$ & $178(46.7 \%)$ \\
\hline Dialytic & 11 & $142(79.8 \%)$ \\
\hline Non-dialytic & 1 & $29(16.3 \%)$ \\
\hline Not reported & 0 & $7(3.9 \%)$ \\
\hline Immune-mediated inflammatory diseases & $83(43.7 \%)$ & $78(20.5 \%)$ \\
\hline Rheumatoid Arthritis & 27 & 20 \\
\hline Systemic Lupus Erythematosus & 17 & 11 \\
\hline Sjogren's syndrome & 1 & 6 \\
\hline Ankylosing spondylitis & 1 & 3 \\
\hline Mixed connective tissue disease & 3 & 2 \\
\hline Inflammatory bowel disease & 14 & 12 \\
\hline Psoriasis & 6 & 7 \\
\hline Scleroderma & 2 & 3 \\
\hline Cutaneous lupus & 1 & 2 \\
\hline Other autoimmune diseases* & 12 & 15 \\
\hline Diabetes mellitus & $11(5.8 \%)$ & $58(15.2 \%)$ \\
\hline Adrenal insufficiency & $13(6.8 \%)$ & $41(10.8 \%)$ \\
\hline Neoplasia & $28(14.7 \%)$ & $18(4.7 \%)$ \\
\hline Hematological & 6 & $12^{\star \star}$ \\
\hline Solid organs & 22 & 6 \\
\hline Chronic liver diseases & $9(4.7 \%)$ & $17(4.5 \%)$ \\
\hline Cirrhotic & 9 & 13 \\
\hline Non-cirrhotic & 0 & 4 \\
\hline HIV & $11(5.8 \%)$ & $16(4.2 \%)$ \\
\hline Neurological diseases & $11(5.8 \%)$ & $5(1.3 \%)$ \\
\hline Multiple sclerosis & 7 & 4 \\
\hline Muscular dystrophy & 2 & 1 \\
\hline Myasthenia gravis & 2 & 0 \\
\hline Chronic lung diseases & 2 & 4 \\
\hline Cardiac insufficiency & 1 & 3 \\
\hline Hematological Diseases & 2 & 4 \\
\hline Primary immunodeficiency & 3 & 1 \\
\hline Other immunodeficiencies & 1 & 0 \\
\hline Solid organ transplantation & 4 & 0 \\
\hline Hematopoietic Stem Cell Transplantation & 1 & 6 \\
\hline Frailty syndrome & 2 & 2 \\
\hline Addison & 2 & 0 \\
\hline Pregnancy & 2 & 0 \\
\hline Egg or erythromycin allergy & 1 & 7 \\
\hline $\begin{array}{l}\text { Neurological events following other vaccines (ADEM - } \\
\text { MMR, GBS - Flu) }\end{array}$ & 0 & 2 \\
\hline Other conditions $\mathbf{s}^{\star \star \star}$ & 5 & 12 \\
\hline Use of immunosuppresssors & $111(58.4 \%)$ & $94(24.7 \%)$ \\
\hline
\end{tabular}

*Other autoimmune diseases - Antiphospholipid syndrome, Behcet's disease, Systemic sclerosis, Dermatomyositis, Lichen planus, Pemphigus, Autoimmune hepatitis, Grave's disease, Hashimoto's disease, Takayasu's arteritis, Temporal arteritis, Celiac disease, Osteoarthritis, unspecified rheumatologic diseases; ${ }^{* *}$ Chronic myeloid leukemia - 8 (5 using Imatinib, 1 dasatinib); Chronic lymphocytic leukemia - 3; Acute lymphocytic leukemia -1 ; ${ }^{* \star}$ Other conditions: Asplenia/Splenectomy, hemangioma, porphyria, bullous epidermolysis, chronic urticaria, eczema, Kawasaki syndrome, sarcoidosis, muscular dystrophy, epilepsy, bariatric surgery, Bannayan-Rilley-Ruvalcaba syndrome, chronic use of corticoids without diagnosis. 
disorders $(78,20.5 \%)$; primary or secondary adrenal insufficiency $(41,10.8 \%)$; neoplasms $(18,4.7 \%)$; chronic liver diseases $(17,4.5 \%)$ and HIV/AIDS (16, 4.2\%) (Table 1). Ten persons living with HIV had CD4 count between 200 and 350 cells $/ \mathrm{mm}^{3}$ and the other six had associated CKD. Several participants had more than one chronic condition, such as rheumatoid arthritis and systemic lupus erythematosus (SLE) or SLE and CKD. Diabetes mellitus was the most frequent associated comorbidity (58 participants, $15.2 \%$ ). Seven persons have also reported mild allergy to egg or erythromycin (none of them reported anaphylaxis).

Ninety-four vaccinees (24.7\%) were using or had recently used immunosuppressive and/ or immunomodulatory drugs; 53 were using corticosteroids and seven were using a prednisone equivalence dosage $\geq 20 \mathrm{mg} /$ day for more than 14 days; 16 were taking MTX, of whom four received $20 \mathrm{mg} /$ week. Two patients used azathioprine but had stopped the medication 2-3 months before vaccination, and another one was still using it when he was vaccinated (50 mg/day; $0.7 \mathrm{mg} / \mathrm{kg} /$ day). One vaccinee had stopped etanercept 3 months before vaccination, 13 were taking chloroquine, five Imatinib, four sulfasalazine or mesalazine, three hydroxyurea and one patient was receiving dasatinib and omalizumab. Patients with solid organ tumors had stopped chemotherapy and/or radiotherapy $\geq 3$ months before vaccination.

We were able to contact (within three months after vaccination) 341 of the 381 vaccinees $(89.5 \%)$. Amongst the 341 contacted vaccinees, 233 (68.3\%) received the YF vaccine from BioManguinhos (12 different batches were used, from 1 to 89 vaccinees by batch) and 108 (31.7\%) received the YF vaccine from Sanofi-Pasteur (just one batch). One hundred and thirty vaccinees (38.1\%) received other vaccines (up to 4) simultaneously. The following vaccines were administered simultaneously: hepatitis B (59 vaccines), pneumococcal polysaccharide 23 -valent (PPV23, 46), influenza (43), diphtheria-tetanus (dT, 41), meningococcal C conjugate (MenCc, 22), hepatitis A (7), measles-mumps-rubella (MMR, 6), and varicella (7).

Two hundred and thirty (67.5\%) vaccinees reported no AEFI; 44 (12.9\%) presented local AEFI and 79 (23.2\%) reported systemic AEFI and 12 persons had both local and systemic AEFI. The most frequently reported AEFI was pain at the injection site (12\%), followed by myalgia $(10 \%)$, fever $(7.3 \%)$ and headache $(4.7 \%)$ (Table 2$)$. Among the 233 persons who received the vaccine from BioManguinhos, 74 (31.75\%) did not present any AEFI, $26(11.15 \%)$ had local AEFI and $54(23.17 \%)$ had systemic AEFI; whereas among the 108 persons who received the vaccine from Sanofi-Pasteur, these features were
37 (34.25\%), 18 (16.66\%), and 25 (23.14\%), respectively (Table 2). AEFI rates did not differ according to the vaccine producer $\left(\chi^{2}\right.$ for any AEFI $=0.21, \mathrm{p}=0.647$ ).

Local AEFI was significantly more frequently reported by persons who received other vaccines simultaneously $(35 / 130,26.9 \%)$ as compared to vaccinees that received only the YF vaccine $\left(9 / 201,4.5 \% ; \chi^{2}=34.5056, \mathrm{p}<.00001\right)$. The frequency of systemic AEFI was also higher in persons who received other vaccines simultaneously $(36 / 130,27.7 \%)$ as compared to vaccinees that received only the YF vaccine (40/201, 19.9\%), but this difference was not statistically significant $\left(\chi^{2}=2.7095, \mathrm{p}=0.1\right)$. Information on other vaccines were not available for 10 vaccinees.

Twelve (3.5\%) vaccinees presented a flu-like syndrome, defined by fever in addition to headache or myalgia: six $(2.8 \%)$ of these vaccinees received the vaccine from BioManguinhos and the other six $(5.5 \%)$ vaccinated with the vaccine from Sanofi-Pasteur. Unsolicited AEFI were reported by 36 persons. Asthenia was the most frequent unsolicited AEFI (9 vaccinees, 2.6\%). The mean time between vaccination and symptoms onset was: 3.68 days, for headache, 3.54 days for myalgia and 4.3 days for fever.

There were four severe AEFI: one hospitalization took place around two weeks after the YF vaccination (vaccine from Sanofi-Pasteur) due to dialysis complications, and there were three deaths. The death certificates were provided by the families to the CRIE staff in all three cases: a 59-yearold man with dialytic CKD due to diabetes mellitus died 3 days after vaccination (vaccine from Sanofi-Pasteur) and the cause of death was an acute myocardial infarction; a 38-year-old woman with dialytic CKD due to eclampsia died 16 days after vaccination (vaccine from Sanofi-Pasteur) from pulmonary thromboembolism; and a 32-year-old man with dialytic CKD who presented an acute febrile disease that started five days after vaccination (vaccine from BioManguinhos) and evolved with septic shock and death 12 days after vaccination. Pneumococcal endocarditis and lung abscesses were observed at autopsy.

\section{DISCUSSION}

It is important to point out that vaccination of immunocompromised persons, described in this observational retrospective study, was conducted during an YF outbreak in a previously transmission-free area. There was a high pressure for vaccination by both, the population and also by physicians who cared for immunocompromised patients. The results suggest the YF vaccines may be used in mildly immunocompromised persons who are clinically stable and live in high-risk areas. In this study, most AEFI were mild and resolved 
Table 2 - Adverse events (AE) following the yellow fever (YF) vaccination reported by 341 immunocompromised persons vaccinated with the vaccine from BioManguinhos or the one from Sanofi-Pasteur at the Reference Center for Immunobiologicals (CRIE) of Hospital das Clinicas of University of Sao Paulo Medical School, from September 2017 to December 2018.

\begin{tabular}{|c|c|c|c|}
\hline $\mathrm{AE}$ following vaccination & $\begin{array}{c}\text { BioManguinhos (233) } \\
\mathrm{n}(\%)\end{array}$ & $\begin{array}{c}\text { Sanofi-Pasteur (108) } \\
\mathrm{n}(\%)\end{array}$ & $\begin{array}{c}\text { Total (341) } \\
\mathrm{n}(\%) \\
\end{array}$ \\
\hline At least one $\mathrm{AE}$ & $74(31.8)$ & $37(34.3)$ & $111(32.6)$ \\
\hline Local AE & $26(11.2)$ & $18(16.7)$ & $44(12.9)$ \\
\hline \multicolumn{4}{|l|}{ Solicited local AE } \\
\hline Pain & $23(9.9)$ & $18(16.7)$ & $41(12.0)$ \\
\hline Edema & 0 & $5(4.6)$ & $5(1.5)$ \\
\hline Erythema & $2(0.8)$ & $1(0.9)$ & $3(0.9)$ \\
\hline Unspecified local AE & $1(0.4)$ & 0 & $1(0.3)$ \\
\hline Systemic AE & $54(23.2)$ & $25(23.2)$ & $79(23.2)$ \\
\hline \multicolumn{4}{|l|}{ Solicited systemic AE } \\
\hline Myalgia & $24(10.3)$ & $10(9.3)$ & $34(10.0)$ \\
\hline Fever & $17(7.3)$ & $8(7.4)$ & $25(7.3)$ \\
\hline Headache & $7(3.0)$ & $9(8.3)$ & $16(4.7)$ \\
\hline \multicolumn{4}{|l|}{ Unsolicited systemic AE } \\
\hline Asthenia & $8(3.0)$ & $1(0.9)$ & $9(2.6)$ \\
\hline Somnolence & $3(1.3)$ & 0 & $3(0.9)$ \\
\hline Nausea/Vomiting & $3(1.3)$ & 0 & $3(0.9)$ \\
\hline Malaise & $2(0.9)$ & $1(0.9)$ & $3(0.9)$ \\
\hline Diarrhea & 0 & $2(1.9)$ & $2(0.6)$ \\
\hline Sore throat & $1(0.4)$ & $1(0.9)$ & $2(0.6)$ \\
\hline Facial edema** & $1(0.4)$ & 0 & \\
\hline Hoarseness & $1(0.4)$ & 0 & $1(0.3)$ \\
\hline Cough & 0 & $1(0.9)$ & $1(0.3)$ \\
\hline Jaundice & $1(0.4)$ & 0 & $1(0.3)$ \\
\hline Papular lesions (on the back of hands and feet) & $1(0.4)$ & 0 & $1(0.3)$ \\
\hline Arrhythmia & $1(0.4)$ & 0 & $1(0.3)$ \\
\hline Joint swelling & 0 & $1(0.9)$ & $1(0.3)$ \\
\hline "Neck heat" & 0 & $1(0.9)$ & $1(0.3)$ \\
\hline Renal colic & 0 & $1(0.9)$ & $1(0.3)$ \\
\hline Lower limbs paresthesia & $1(0.4)$ & 0 & $1(0.3)$ \\
\hline Lymphadenomegaly & $1(0.4)$ & 0 & $1(0.3)$ \\
\hline Abdominal pain & $1(0.4)$ & 0 & $1(0.3)$ \\
\hline Pruritus & $1(0.4)$ & 0 & $1(0.3)$ \\
\hline Chills & $1(0.4)$ & 0 & $1(0.3)$ \\
\hline$\underline{\text { Hypertensive episode }}$ & $1(0.4)$ & 0 & $1(0.3)$ \\
\hline Severe $A E^{\star \star \star}$ & $1(0.4)$ & $3(2.8)$ & $4(1.2)$ \\
\hline Hospitalization & 0 & $1(0.9)$ & $1(0.3)$ \\
\hline Death & $1(0.4)$ & $2(1.9)$ & $3(0.9)$ \\
\hline
\end{tabular}

*12 vaccinees had both, local and systemic AE. Each vaccinee may have had $\geq 1$ symptom; ${ }^{* *} A$ boy aged 57 months with history of egg allergy had facial edema that regressed with antiallergic drugs; ${ }^{* \star *}$ None of the severe AEFI was considered related to the vaccination.

spontaneously without complications. Four severe AEFI were reported (one hospitalization and three deaths), that were considered not related to the YF vaccination. All severe AEFIs occurred in patients with dialytic CKD. The deaths were considered not related to the YF vaccines based on the death certificates that contained well-defined causes of death.
We detected a higher frequency of any of the AEFI $(32.5 \%)$, such as fever $(7 \%)$ and reactions at the injection site (12.9\%) after the YF vaccination of immunocompromised persons in comparison with the previously reported frequencies in immunocompetent persons ${ }^{9}$. No differences on AEFI rates according to the vaccine producer were observed. The package insert of the YF vaccine from 
BioManguinhos states that 2-5\% of vaccinees may present headache, myalgia, fever and other mild symptoms from the $5^{\text {th }}$ to the $10^{\text {th }}$ day following vaccination. The package insert of the YF vaccine from Sanofi-Pasteur informs that mild injection site reactions, such as erythema and pain, and systemic reactions, such as headache and fever, occurs typically in less than $5 \%$ of vaccinees, 5 to 7 days after vaccination. A randomized controlled trial that evaluated the YF vaccine from BioManguinhos in adults found that up to $20.9 \%$ of vaccinees have at least one $\mathrm{AEFI}^{9}$. The most frequent AEFI was headache (12.8\%), followed by flu-like syndrome, defined as myalgia associated with headache and fever $(7.1 \%)$, and myalgia (6.7\%); injection site reactions were reported by $3.3 \%$, and fever and nausea by $3 \% \mathrm{each}^{9}$. According to WHO, "in clinical trials, mild adverse events, such as headache, myalgia, low-grade fever, discomfort at the injection site, pruritus, urticaria and rash were reported by up to $25 \%$ of vaccinees" 10 .

Simultaneous vaccination, administered to $38.1 \%$ of persons in this study, may increase AEFI rates. In addition, local AEFIs were statistically associated with multiple vaccinations. Persons with chronic conditions/ immunocompromised are commonly unaware of recommended vaccines for their health conditions. In the healthcare practice, we take advantage of every visit to the vaccine room to update the immunization. Most AEFIs are mild and self-limited and should not be a reason to withhold multiple vaccinations when they are needed.

There are few reports of YF vaccination in immunocompromised persons in the literature, most of them retrospective studies describing the inadvertent vaccination of only a few persons. Available data on the $\mathrm{YF}$ vaccine safety in this group is very scarce and potential risks are serious, including death. There is a report of fatal encephalitis following the YF vaccination in a person with asymptomatic HIV unaware of his condition ${ }^{11}$. A Brazilian study involving 70 rheumatic patients using immunosuppressors reported 16 (22.9\%) minor AEFIs. Among eight patients using immunobiological agents, only one presented a mild $\mathrm{AEFI}^{12}$. Another study described the YF vaccination in 17 patients with rheumatoid arthritis receiving infliximab and MTX. No AEFI was observed, but all the vaccinees had received a previous YF vaccine dose $\geq$ 10 years before and most of them (10/12) were seropositive before revaccination ${ }^{13}$. A systematic review to access the safety of live vaccines in patients with immune-mediated inflammatory diseases or solid organ transplantation on immunosuppressive treatment and hematopoietic stem-cell transplantation included 64 articles that reported 253 administered YF vaccine doses. A patient with rheumatoid arthritis and systemic lupus erythematosus (SLE), who started MTX/ dexamethasone treatment four days after the YF vaccination had YEL-AVD and died ${ }^{14}$. There are several reports of YEL-AVD in persons with immune-mediated inflammatory diseases, particularly SLE ${ }^{6,15}$. The potential risk of severe AEFIs in this population is not known and vaccines should be used only in high risk situations, preceded by a careful individual screening.

A French study interviewed 34 adult travelers who had received the YF 17D vaccine while on systemic corticosteroid therapy (median duration, 10 months; prednisone equivalent dosage, $7 \mathrm{mg} /$ day). No serious AEFI was reported, but they have also found that vaccinees receiving corticosteroids reported more frequent moderate/severe local reactions (12\%) than controls $(2 \%)^{16}$. A study conducted in travel clinics in Zurich retrospectively identified and interviewed 116 travelers on immunosuppressive/ immunomodulatory therapy who had received live attenuated vaccines; 92 doses of YF vaccine were administered ${ }^{17}$. A patient with rheumatoid arthritis using sulfasalazine reported severe myalgia and arthralgia after the YF vaccination ${ }^{17}$.

A cross-sectional study assessed the YF vaccination among 130 patients with dialytic CKD; 45 patients received the YF vaccine, of whom 21 had never been vaccinated before $^{18}$. AEFI were reported by $26.7 \%$ (12/45) vaccinees, with mild local AEFI in 11 (24.4\%). Two patients had fever, which resolved in $24 \mathrm{~h}$. No serious AEFI was reported ${ }^{17,18}$.

Another study retrospectively identified 19 solid organ transplanted patients who inadvertently received the YF vaccine and one of them reported mild reaction at the injection site and none reported systemic $\mathrm{AEFI}^{19}$. However, cases series that retrospectively identified vaccinees among patients in follow-up may not be able to identify deaths related to serious AEFI.

The present study has limitations. This is an observational study, but considering the YF vaccine contraindication for immunocompromised persons, it will be considered for this population only in high-risk settings, such as outbreaks/epidemics, when a controlled trial would not be possible/ethical. The decision on vaccinating (or not) an individual was taken in the care practice by five attending physicians and, although we have tried to standardize the recommendations/contraindications, differences among their conducts may have happened. Furthermore, we evaluated several different conditions and drugs that make their individual analysis not feasible. Finally, our sample size was small, inappropriate to evaluate rare events and we were not able to contact $10.5 \%$ of the vaccinees. However, the vaccinees were oriented regarding possible AEFI and advised to return to the service in case of AEFI, and we contacted them in a short period of time after vaccination 
(15-90 days) making it easier for them to remember AEFIs.

This study was carried out during an outbreak of YF, with great stress, due to both, the demand for the vaccine and the fear of YF urbanization. New prospective studies with specific populations, larger sample sizes, including viremia assessment and healthy controls are needed. Even though, we believe that our results allow us to conclude that the YF vaccine may be administered to mildly immunocompromised, clinically stable persons living in high-risk areas, always preceded by a careful individual assessment, weighing the benefits and risks of vaccination.

\section{ACKNOWLEDGMENTS}

We thank the entire CRIE staff for supporting this work.

\section{AUTHORS' CONTRIBUTIONS}

ANL, AMCS: literature search, tables, data collection, writing, revision; KTM: data collection, revision; KYI, MHL: data collection, revision.

\section{REFERENCES}

1. Possas C, Lourenço-de-Oliveira R, Tauil PL, Pinheiro FP, Pissinatti A, Cunha RVD, et al. Yellow fever outbreak in Brazil: the puzzle of rapid viral spread and challenges for immunisation. Mem Inst Oswaldo Cruz. 2018;113:e180278.

2. Brasil. Ministério da Saúde. Secretaria de Vigilância em Saúde. Emergência epidemiológica de febre amarela no Brasil, no período de dezembro de 2016 a julho de 2017. Bol Epidemiol. 2017;48:1-22.

3. Brasil. Ministério da Saúde. Informe $\mathrm{N}^{\circ} 27$ : monitoramento do período sazonal da febre amarela: Brasil - 2017/2018. [cited 2020 Oct 14] Available from: https://portalarquivos2.saude. gov.br/images/pdf/2018/outubro/08/Informe-FA.pdf

4. Cavalcante KR, Tauil PL. Risk of re-emergence of urban yellow fever in Brazil. Epidemiol Serv Saude. 2017;26:617-20.

5. World Health Organization. Yellow fever: Brazil. [cited 2020 Oct 14]. Available from: http://who.int/csr/don/04-april-2017yellow-fever-brazil/en/

6. Martins RM, Maia ML, Santos EM, Cruz RL, Santos PR, Carvalho $\mathrm{SM}$, et al. Yellow fever vaccine post-marketing surveillance in Brazil. Procedia Vacinnol. 2010;2:178-83.

7. Seligman SJ. Risk groups for yellow fever vaccine-associated viscerotropic disease (YEL-AVD). Vaccine. 2014;32:5769-75.

8. Sociedade Brasileira de Reumatologia. Sociedade Brasileira de Infectologia. Sociedade Brasileira de Medicina Tropical.
Nota técnica conjunta sobre vacinação para a febre amarela (VFA) em pacientes com doenças reumáticas imunomediadas (DRIM). [cited 2020 Oct 14]. Available from: https:// www.reumatologia.org.br/downloads/pdf/nota-sociedadesvacina\%C3\%A7\%C3\%A3o-febre-amarela-2018.pdf

9. Camacho LA, de Aguiar SG, Freire MS, Leal ML, do Nascimento JP, Iguchi T, et al. Reactogenicity of yellow fever vaccines in a randomized, placebo-controlled trial. Rev Saude Publica. 2005;39:413-20.

10. World Health Organization. Vaccines and vaccination against yellow fever. WHO position paper - June 2013. Wkly Epidemiol Rec. 2013;88:269-83.

11. Kengsakul K, Sathirapongsasuti K, Punyagupta S. Fatal myeloencephalitis following yellow fever vaccination in a case with HIV infection. J Med Assoc Thai. 2002;85:131-4.

12. Mota LM, Oliveira AC, Lima RA, Santos-Neto LL, Tauil PL. Vacinação contra febre amarela em pacientes com diagnósticos de doenças reumáticas, em uso de imunossupressores. Rev Soc Bras Med Trop. 2009;42:23-7.

13. Scheinberg M, Guedes-Barbosa LS, Mangueira C, Rosseto EA, Mota L, Oliveira AC, et al. Yellow fever revaccination during infliximab therapy. Arthritis Care Res (Hoboken). 2010;62:896-8.

14. Croce E, Hatz C, Jonker EF, Visser LG, Jaeger VK, Bühler S. Safety of live vaccinations on immunosuppressive therapy in patients with immune-mediated inflammatory diseases, solid organ transplantation or after bone-marrow transplantation: a systematic review of randomized trials, observational studies and case reports. Vaccine. 2017;35:1216-26.

15. Seligman SJ. Yellow fever virus vaccine-associated deaths in young women. Emerg Infect Dis. 2011;17:1891-3.

16. Kernéis S, Launay O, Ancelle T, Iordache L, Naneix-Laroche $\mathrm{V}$, Méchaï F, et al. Safety and immunogenicity of yellow fever 17D vaccine in adults receiving systemic corticosteroid therapy: an observational cohort study. Arthritis Care Res (Hoboken). 2013;65:1522-8.

17. Huber F, Ehrensperger B, Hatz C, Chappuis F, Bühler S, Eperon G. Safety of live vaccines on immunosuppressive or immunomodulatory therapy: a retrospective study in three Swiss travel clinics. J Travel Med. 2018;25:tax082.

18. Facincani T, Guimarães MN, Santos SS. Yellow fever vaccination status and safety in hemodialysis patients. Int J Infect Dis. 2016;48:91-5.

19. Azevedo LS, Lasmar EP, Contieri FL, Boin I, Percegona L, Saber LT, et al. Yellow fever vaccination in organ transplanted patients: is it safe? A multicenter study. Transpl Infect Dis. 2012;14:237-41. 